\title{
Transfection with Livin and Survivin shRNA inhibits the growth and proliferation of non-small cell lung cancer cells
}

\author{
QINMIAO HUANG, YIMING ZENG, HUIHUANG LIN, HUAPING ZHANG and DONGYONG YANG \\ Department of Respiratory Medicine, The Second Affiliated Hospital of \\ Fujian Medical University, Quanzhou, Fujian 362000, P.R. China
}

Received December 20, 2016; Accepted July 25, 2017

DOI: $10.3892 / \mathrm{mmr} .2017 .7490$

\begin{abstract}
Lung cancer is reported to be a major public health issue worldwide and the overall prognosis of patients remains poor. The expression levels of Livin and Survivin, of the inhibitors of apoptosis (IAP) family, are associated with prognostic significance in the majority of solid tumors. Therefore, in the presents study, short hairpin (sh)RNA expression vectors inhibiting the Livin and Survivin genes were constructed to examine the effects of the transfection of Livin shRNA and/or Survivin shRNA on the biological functions of tumor cells. The transfection efficiency was measured using fluorescence reverse transcription-quantitative polymerase chain reaction and western blot analyses. The cell growth inhibition ratio was measured using a CCK assay. Cell apoptosis following transfection and in tumor tissues were measured using a TUNEL assay, and a cancer xenograft model was used to investigate the effect of Livin shRNA and/or Survivin shRNA on tumor growth. The results indicated that the mRNA and protein expression levels were suppressed following the transfection of Livin and Survivin shRNA into tumor cells $(\mathrm{P}<0.05$, compared with control group). The growth of tumor cells in vivo and in vitro was significantly inhibited following transfection with Livin and Survivin shRNA, compared with that in the other groups $(\mathrm{P}<0.05)$. Taken together, the transfection of cells with Livin and Survivin inhibited tumor growth in vivo and in vitro, with the co-transfection of Livin and Survivin shRNA showing increased efficiency, compared with transfection of either the Livin vector or Survivin vector alone. The combined inhibition of Livin and Survivin may be a promising multitargeted gene therapeutic strategy in cancer treatment.
\end{abstract}

Correspondence to: Dr Qinmiao Huang, Department of Respiratory Medicine, The Second Affiliated Hospital of Fujian Medical University, 34 North Zhongshan Road, Quanzhou, Fujian 362000, P.R. China

E-mail: drhuangqinmiao@126.com

Key words: Livin, Survivin, RNA interference, tumor, proliferation, apoptosis

\section{Introduction}

Lung cancer is the main cause of cancer-associated mortality worldwide, representing almost one in five cases of cancer-associated mortality, with non-small cell lung cancer (NSCLC) accounting for three in four cases of lung cancer. A large proportion of patients with NSCLC succumb to mortality in the first few years following diagnosis, and the morbidity and mortality rates remain high at 5 years. Although advances in the treatment of NSCLC have improved patient prognosis, $>50 \%$ of patients with NSCLC are diagnosed at an advanced stage of disease, and there is currently no curative therapy for these patients $(1,2)$. In the treatment of lung cancer, $>90 \%$ of patients with lung cancer are managed with conventional therapy, including surgery, radiation and chemotherapy, however, their efficacy remains limited and it is difficult to achieve complete remission or cure (3-5).

Less invasive therapies to control local tumor development and metastasis, including minimally invasive and less radical removal, in addition to image-guided ablative approaches are currently used in the treatment of early-stage NSCLC (6).

Compared with small interfering RNA (siRNA), vector-based RNA interference (RNAi) provides a prolonged duration of gene silencing and has attracted increased interest; the application of RNAi to downregulate oncogene expression and alter the biological behavior of tumor cells represents the newest type of treatment for NSCLC (7).

Livin and Survivin, of the inhibitors of apoptosis (IAP) family, are reported to be associated with the development and prognosis of tumors, and are expressed at high levels in the majority of tumor cells, including prostatic cancer, osteosarcoma, bladder cancer and lung cancer (8-10). Therefore, Survivin and Livin may be novel promising targets in cancer therapy. Yang et al reported that the dual short hairpin RNA (shRNA) silencing of Livin and Survivin genes significantly inhibited their expression levels in PC-3M prostate cancer cells, reduced proliferation and facilitated apoptosis of the PC-3M cells (11). Guan et al indicated that the mPEG-CSNPs mediated Livin and Survivin interference, significantly decreasing their expression in MG-63 osteosarcoma cells, suppressing the proliferation and promoting the apoptosis of osteosarcoma cells (10). It has been reported that Livin and Survivin, in addition to X-linked inhibitor of apoptosis (XIAP), have a synergistic effect reducing cellular proliferation and promoting 
the apoptosis of human bladder cancer cells (12). Zhang et al also reported that the overexpression of Sharpin activated the nuclear factor- $\kappa \mathrm{B}$ pathway and downstream targets Survivin and Livin, potentially promoting the development of prostate cancer (13).

However, whether the double silencing of Livin and Survivin has any synergistic effect on the growth, proliferation and apoptosis of human NSCLC remains to be elucidated. In the present study, eukaryotic expression vectors encoding Livin and Survivin shRNAs were designed and constructed for transfection or co-transfection into human NSCLC cells to examine the effects of single shRNA silencing and double silencing on the biological function of human NSCLC cells.

\section{Materials and methods}

Cell culture. The A549 human lung cancer cell line was purchased from the Cell Bank of Shanghai Institutes for Biological Sciences, Chinese Academy of Sciences (Shanghai, China). The A549 cells were cultured in RPMI-1640 medium with $10 \%$ heat inactivated fetal bovine serum (FBS) (Gibco; Thermo Fisher Scientific, Inc., Waltham, MA, USA) in a humidified incubator with $5 \% \mathrm{CO}_{2}$ at $37^{\circ} \mathrm{C}$.

Construction of shRNA expression vectors. The Livin (Gene ID: 79444) and Survivin (Gene ID: 332) mRNA sequences were obtained from the NCBI database (www.ncbi.nlm.nih.gov/pubmed) according to a previous study (14). The pSILENCER-3.0H1 expression vector (Ambion; Thermo Fisher Scientific, Inc.) contained a human H1 polymerase-III promoter for shRNA expression. According to the methods described previously $(15,16)$, the following 19 nucleotide siRNA target sequences were designed: Livin, 5'-GGAAGAGACTTTGTCCACA-3'; Survivin, 5'-GGACCA CCGCATCTCTACA-3'. Each shRNA insert was designed as a synthetic duplex with overhanging ends identical to those created by BamHI restriction enzyme digestion at the $5^{\prime}$ end and HindIII restriction enzyme digestion at the $3^{\prime}$ end. There was a nine-nucleotide ring sequence (TTCAAGAGA) between the strand and antisense strands. Following digestion by the BamHI/HindIII restriction endonucleases, the two sequences were inserted into the pSILENCER-3.0H1 plasmid by ligating the same restriction enzyme-digested shRNA fragment to the vector.

Transfection. Transfection was performed using Lipofectamine ${ }^{\circledR}$ LTX reagent according to the manufacturer's protocol. At $24 \mathrm{~h}$ prior to transfection, the A549 cells were harvested and $2.5 \times 10^{5}$ cells were plated in each well of a 6 -well plate in DMEM (Gibco; Thermo Fisher Scientific, Inc.) with $10 \% \mathrm{FBS}$ at $5 \% \mathrm{CO}_{2}, 37^{\circ} \mathrm{C}, 95 \%$ humidity. When the cells reached $50-80 \%$ confluence, the culture medium was removed and replaced with $2 \mathrm{ml}$ of complete culture medium. For the transfection of cells in each well, $2.5 \mu \mathrm{g}$ of plasmid diluted in $100 \mu \mathrm{l}$ of Opti-MEM ${ }^{\circledR}$ I reduced serum medium (0\% serum), following which Lipofectamine LTX $^{\circledR}$ reagent (3.75-8.75 $\mu \mathrm{l})$ was added into the above diluted solution. The DNA-Lipofectamine LTX $^{\circledR}$ reagent complexes formed following gentle mixing of the solution and incubation at room temperature for $30 \mathrm{~min}$. The DNA-Lipofectamine LTX $^{\circledR}$ reagent complexes $(500 \mu \mathrm{l})$ were added directly to each well containing $2.5 \times 10^{5}$ cells and mixed gently by rocking the plate back and forth for $30 \mathrm{~min}$. The complexes were not removed following transfection. Prior to transgene expression assaying, the transfected cells were incubated at $37^{\circ} \mathrm{C}, 5 \% \mathrm{CO}_{2}$ for $24 \mathrm{~h}$ following transfection. The cells were divided into four groups: pSilencer-Livin transfection group; pSilencer-Survivin transfection group; pSilencer-Survivin and pSilencer-Livin double-transfection group; and no transfection group (control group).

mRNA expression levels of Livin and Survivin. Fluorescent reverse transcription-quantitative polymerase chain reaction (RT-qPCR) analysis was performed to determine the expression levels of Survivin and Livin according to a previous study (17). Following transfection for $72 \mathrm{~h}$, the cells were harvested and total RNA extraction was performed using TRIzol reagent (Sigma-Aldrich; Merck Millipore, Darmstadt, Germany). PrimeScript RT Master Mix (Takara Bio, Inc., Otsu, Japan) was used to perform reverse transcription according to the manufacturer's protocol. Briefly, $2 \mu 15 \mathrm{X}$ Primer Script mix, $3 \mu 1$ RNase-free water and $5 \mu$ l total RNA were added to the reaction system. The mixture was incubated for $15 \mathrm{~min}$ at $37^{\circ} \mathrm{C}$, and then at $85^{\circ} \mathrm{C}$ for $5 \mathrm{sec}$, following which the mixture was maintained at $4^{\circ} \mathrm{C}$. The primer sequences were as follows: Survivin, forward 5'-ATTCGCAGACTGGCCCTTTA-3' and reverse 5'-AGAGGAAACCACAGTTGGCAG-3'; Livin, forward 5'-AGGGCGTGGTGGGTTCTTG-3' and reverse 5'-CGGCACAAAGACGATGGACA-3'. The ABI PRISM 7000 sequence detection system and SYBR-Green PCR Master mix (Applied Biosystems; Thermo Fisher Scientific, Inc.) were used to perform RT-qPCR. The PCR sample volume of $25 \mu \mathrm{l}$ consisted of $12.5 \mu \mathrm{l}$ SYBR-Green PCR Master mix, $300 \mathrm{nM}$ forward primers and reverse primers, and $2.0 \mu \mathrm{l}$ template cDNA (diluted 1:20). The PCR cycle consisted of a total of 40 cycles, the parameters were as follows: Pre-degeneration for $30 \mathrm{sec}$ at $95^{\circ} \mathrm{C}$; followed by denaturation at $95^{\circ} \mathrm{C}$ for $5 \mathrm{sec}$ and annealing at $60^{\circ} \mathrm{C}$ for $20 \mathrm{sec}$, and then melting curve analysis for $15 \mathrm{sec}$ at $65^{\circ} \mathrm{C}$. The $2^{-\Delta \Delta \mathrm{Cq}}$ method (18), with a reference gene $(\beta$-actin, forward 5'-GAACGGTGAAGGTGA CAG-3' and reverse 5'-TAGAGAGAAGTGGGGTGG-3') as an internal standard, was used to determine the relative gene expression.

Western blot analysis. The protein expression levels of Livin and Survivin were determined using western blot analysis (19). At $48 \mathrm{~h}$ post-transfection, cells were lysed with lysis buffer (Invitrogen; Thermo Fisher Scientific, Inc.) with protease inhibitor cocktail tablets (Roche Diagnostics $\mathrm{GmbH}$, Mannheim, Germany) and phosphatase inhibitors (1 $\mathrm{mM} \mathrm{NaF}$

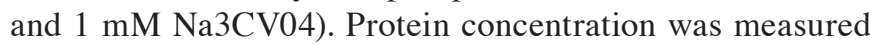
using a protein assay kit (Bio-Rad Laboratories, Inc., Hercules, CA, USA) with bovine serum albumin (Bio-Rad Laboratories, Inc.) as the standard. Proteins $(15 \mu \mathrm{g} /$ lane $)$ were separated on $10 \%$ SDS-PAGE gels, and these were transferred onto nitrocellulose membranes. Subsequently, 5\% w/v non-fat dry milk in Tris-buffered saline and Tween-20 (TBST) buffer, containing $20 \mathrm{mmol} / \mathrm{l}$ Tris- $\mathrm{HCl}$ (pH 7.4), $150 \mathrm{mmol} / \mathrm{l} \mathrm{NaCl}$ and $0.05 \%$ Tween-20, was used to block the membranes at room temperature for $1 \mathrm{~h}$. The membranes were then incubated with 
A

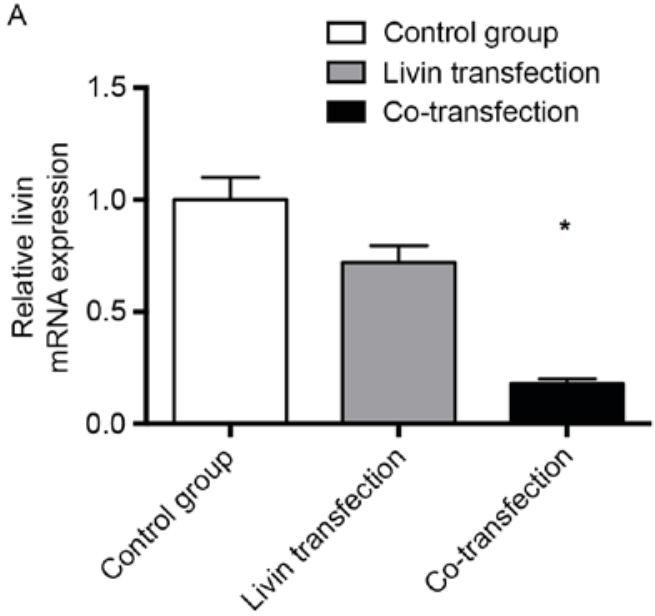

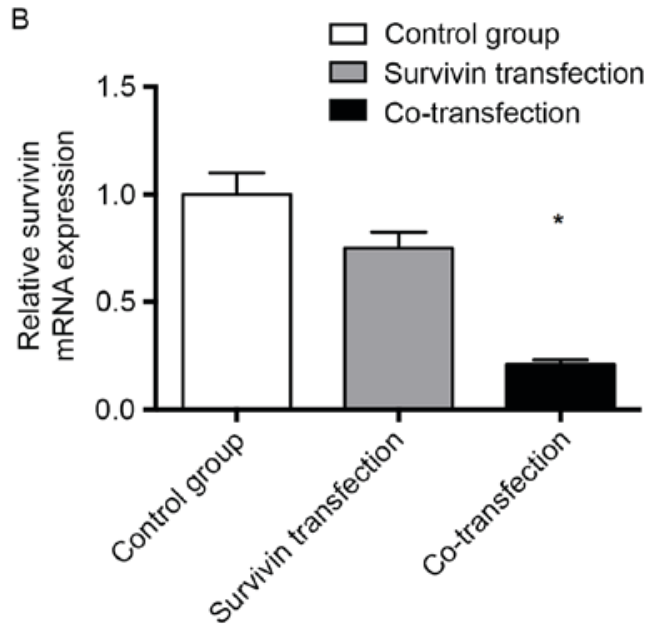

Figure 1. Reverse transcription-quantitative polymerase chain reaction analysis. (A) Relative mRNA expression of Livin in the Survivin shRNA and Livin shRNA co-transfection group was lower than its expression in the Livin shRNA transfection group at $48 \mathrm{~h}$ post-transfection ( $<<0.05)$. (B) Relative mRNA expression of Survivin in the co-transfection group was lower than its expression in the Survivin shRNA transfection group at $48 \mathrm{~h}$ post-transfection $(\mathrm{P}<0.05)$. This indicated that shRNA transfection decreased the mRNA expression levels of Livin and Survivin, and that co-transfection was more efficient than single transfection with either Survivin shRNA or Livin shRNA alone. ${ }^{*}<0.05$ as compared with control. shRNA, short hairpin RNA.

primary antibodies at room temperature for $1 \mathrm{~h}$. Primary antibodies were as follows: Survivin rabbit mAb (cat. no. 2808; 1:1,000; Cell Signaling Technology, Inc., Danvers, MA, USA) and livin rabbit mAb (cat. no. 5471; 1:1,000; Cell Signaling Technology, Inc.). Following three 15-min washes in TBST, the membranes were incubated with individual secondary antibodies [anti-rabbit IgG horseradish peroxidase (HRP)-linked antibody, cat. no. 7074 and anti-biotin HRP-linked antibody, cat. no. 7075; both 1:2,000; Cell Signaling Technology, Inc.] at room temperature for $1 \mathrm{~h}$, followed by three 10 -min washes with TBST. The subsequent signal generation was performed using a Perfect Protein Western Blot kit (Novagen, Inc., Madison, WI, USA). The membrane was visualized with ECL Western Blotting Detection reagents (GERPN2209; Sigma-Aldrich; Merck KGaA). Image J software (ImageJ2x 2.1.4.7; National Institutes of Health, Bethesda, MD, USA) was used for densitometric analysis and the relative protein levels were evaluated using GADPH (cat. no. 8884; 1:1,000; Cell Signaling Technology, Inc.) as the control.

CCK assay. The cells were seeded into each well of a 96-well plate $\left(1 \times 10^{3}\right.$ cells/well) $24 \mathrm{~h}$ prior to transfection and were divided into the four groups described above. The transfection procedure was performed according to the protocol described above. Following transfection, the cells were cultured for 24, 48 or $72 \mathrm{~h}$ at $37^{\circ} \mathrm{C}$ in $5 \% \mathrm{CO}_{2}$, respectively. The optical density (OD) values were measured at an absorbance of $490 \mathrm{~nm}$. The inhibition rate of cell proliferation was calculated using the following formula: (1-experimental group OD value/control group OD) x $100 \%$.

Cancer cell xenograft model and plasmid injection. The use of animals in the present study was approved by the Institutional Approval Board of The Second Affiliated Hospital of Fujian Medical University (Quanzhou, China). The human cancer cell xenograft models were constructed according to a previous study (20). In brief, the A549 cells were obtained and washed with PBS three times, re-suspended in RPMI-1640 medium with $10 \% \mathrm{FBS}$, and injected $\left(2 \times 10^{6}\right.$ cells) into the flank regions of athymic nude (nu/nu) mice (male; age, 8 weeks; weight, $20 \mathrm{~g}$ ). A total of 36 mice were supplied by the Laboratory Animal Center, Fujian Medical University and housed under standard animal housing conditions, with a temperature of $22 \pm 1^{\circ} \mathrm{C}$, a 12 -h light/dark cycle and free access to food and water. Following tumor development, the tumor fragments were transplanted subcutaneously into the flanks of both sides of nude mice, following which the mice were randomly divided into four groups ( $\mathrm{n}=6 /$ group): shRNA-Livin injection group; shRNA-Survivin injection group; shRNA-Survivin and shRNA-Livin double-injection group; and PBS group (control group). When the volume of the tumors reached $50-100 \mathrm{~mm}^{3}$, the mice were administered with shRNA plasmids in $500 \mu \mathrm{l}$ PBS via injection into the tail vein three times each week for 6 weeks. The tumor diameters were calculated during the injection period and for 4-6 weeks following the final injection.

Analysis of apoptosis. The apoptosis of cells was detected using a TUNEL assay. The cells were seeded onto a $25 \mathrm{~cm}^{2}$ plate $24 \mathrm{~h}$ prior to transfection, and divided into the four groups. At $48 \mathrm{~h}$ post-transfection, $4 \%$ paraformaldehyde was used to fixed non-adherent cells and adherent cells, and the cells were permeabilized with a solution of $0.1 \%$ Triton $\mathrm{X}-100$ in $0.1 \%$ sodium citrate, followed by incubation for $1 \mathrm{~h}$ in the TUNEL reaction mixture at room temperature (Roche Diagnostics $\mathrm{GmbH})$. The cells were washed with PBS three times, and the TUNEL-positive (FL1 $>10^{1}$ ) cells were analyzed by FACS analysis using CellQuest version 5.1 software following flow cytometry (BD Biosciences, Franklin Lakes, NJ, USA) (1).

To examine apoptosis in the tumor tissues, the mice were sacrificed following the final injection, and the tumor tissues were harvested and fixed in $4 \%$ paraformaldehyde in PBS and embedded in paraffin. The tumor tissues were cut into $5-\mu \mathrm{m}$ thick tissue sections, and the sections were de-paraffinized in xylene, rehydrated in reduced grades of alcohol and then washed in PBS. The rehydrated slides were permeabilized in $0.1 \%$ Triton $\mathrm{X}-100$ and $0.1 \%$ sodium citrate, 

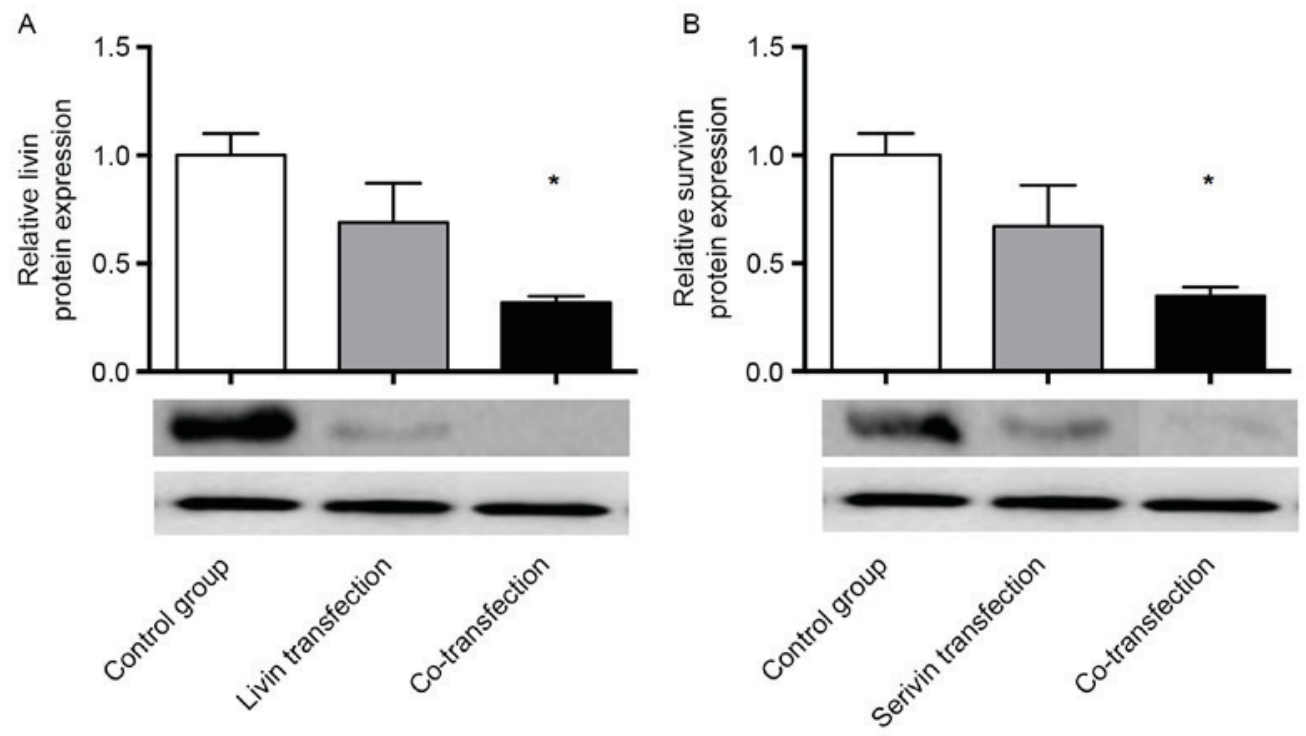

Figure 2. Western blot analysis. (A) Relative protein expression of Livin was lower in the co-transfection group than in the Livin shRNA transfection group at $48 \mathrm{~h}$ post-transfection $(\mathrm{P}<0.05)$. (B) Relative protein expression of Survivin was lower in the co-transfection group than in the Survivin shRNA transfection group $(\mathrm{P}<0.05)$. shRNA transfection decreased the protein expression levels of Livin and Survivin, and co-transfection was more efficient than single transfection with either Survivin shRNA or Livin shRNA alone. ${ }^{*} \mathrm{P}<0.05$ as compared with control. shRNA, short hairpin RNA.

and then incubated in the TUNEL reaction mixture at $37^{\circ} \mathrm{C}$ in humidified conditions for $1 \mathrm{~h}$. The sections were then washed in PBS and observed under a fluorescence microscope. Fluorescence values were calculated from three randomly selected fields per section and expressed as the mean \pm standard deviation.

Statistical analysis. The data are presented as the mean \pm standard deviation and were analyzed by one-way analysis of variance with a Newman-Keuls post hoc test using SPSS 17.0 software (SPSS, Inc., Chicago, IL, USA). P<0.05 was considered to indicate a statistically significant difference.

\section{Results}

Relative mRNA expression of Livin and Survivin. In order to evaluate the effects of Livin shRNA and/or Survivin shRNA transfection on mRNA levels, fluorescent RT-qPCR was used to evaluate the relative mRNA expression levels of Livin and Survivin. Following transfection for $48 \mathrm{~h}$, the relative mRNA expression of Livin was $0.18 \pm 0.02$ in the Survivin shRNA and Livin shRNA co-transfection group, which was lower than that in the Livin shRNA transfection group $(0.72 \pm 0.17$; Fig. 1A). The relative mRNA expression of Survivin was $0.21 \pm 0.02$ in the Survivin shRNA and Livin shRNA co-transfection group, which was lower than that in the Survivin shRNA transfection group $(0.75 \pm 0.15$; Fig. 1B), indicating that shRNA transfection decreased the mRNA expression levels of Livin and Survivin. Co-transfection was more efficient than single transfection with either Survivin shRNA or Livin shRNA alone (Fig. 1).

Protein expression of Livin and Survivin. Western blot analysis was performed to measure the protein expression levels of Livin and Survivin. Following transfection for $48 \mathrm{~h}$, the relative protein expression of Livin was $0.32 \pm 0.03$ in the co-transfection group, which was lower than that in the Livin

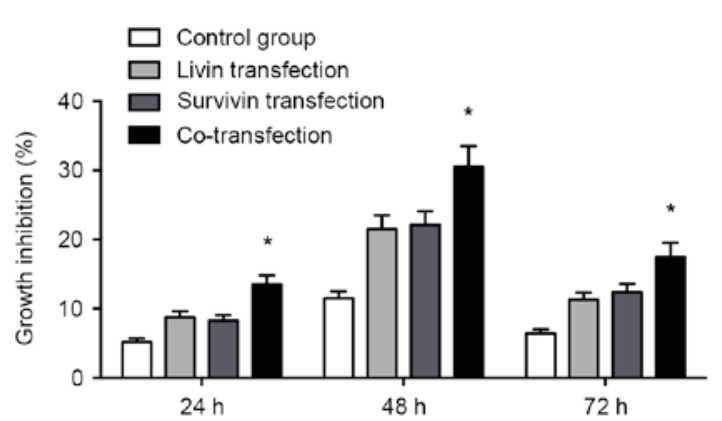

Figure 3. CCK assay. Transfection with Livin and/or Survivin shRNA inhibited the proliferation of A549 cells. The cell proliferation in the co-transfection group showed a higher rate of growth inhibition, compared with that in either the Livin shRNA or Survivin shRNA transfection group $(\mathrm{P}<0.05) .{ }^{*} \mathrm{P}<0.05$ as compared with control. shRNA, short hairpin RNA.

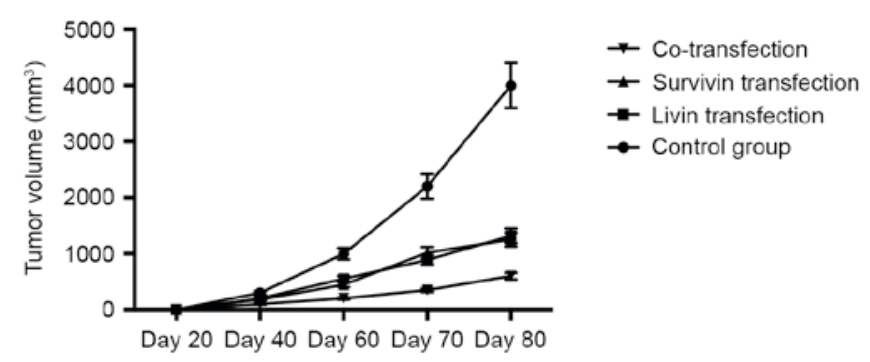

Figure 4. Antitumor effects in vivo. The injection of shRNA plasmids significantly inhibited tumor growth in mice, compared with that in the untreated group. Co-transfection with Livin and Survivin shRNA exerted a more marked effect, compared with either Livin or Survivin shRNA alone. shRNA, short hairpin RNA.

shRNA transfection group $(0.69 \pm 0.18$; Fig. $2 \mathrm{~A})$. The relative protein expression of Survivin was $0.35 \pm 0.04$ in the co-transfection group, which was lower than that in the Survivin shRNA transfection group $(0.67 \pm 0.19$; Fig. $2 B)$, indicating that 
A

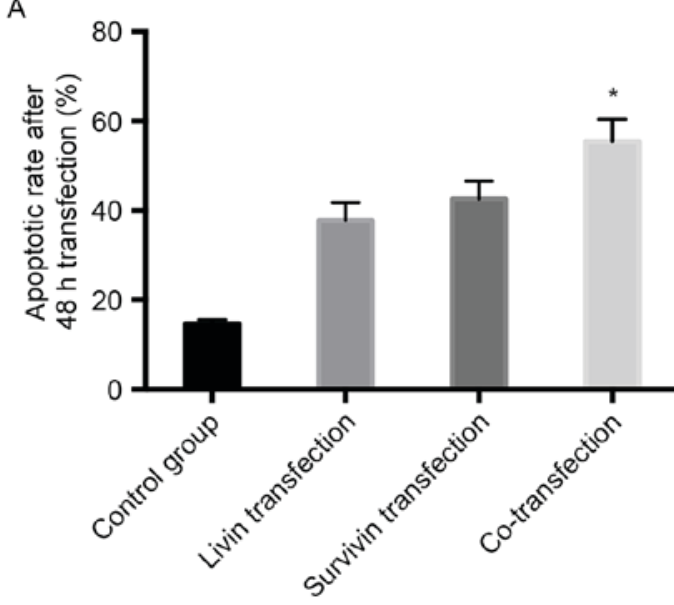

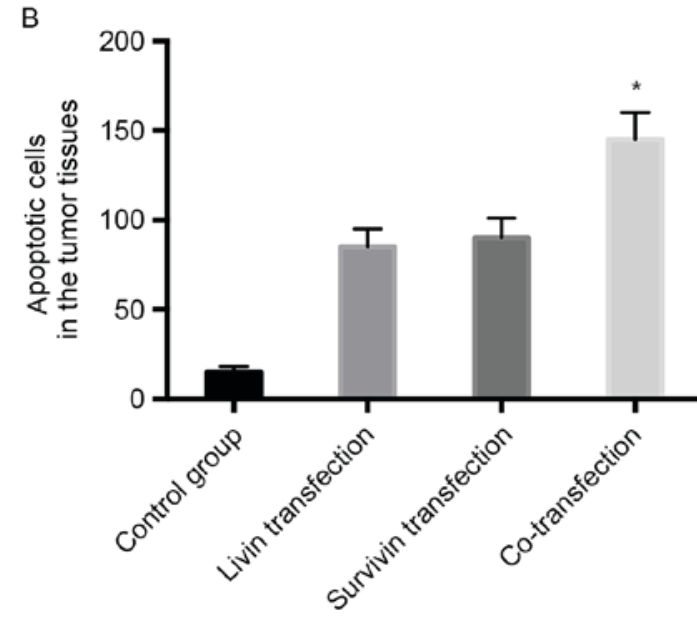

Figure 5. Apoptosis. (A) Transfection with Livin and/or Survivin shRNA promoted cell apoptosis following transfection for 48 h, and the apoptotic rate in the co-transfected group was higher than that in either the Livin shRNA or Survivin shRNA group $(\mathrm{P}<0.05)$. This indicated that Livin and Survivin co-transfection was more effective in promoting apoptosis. (B) Co-transfection with Livin and Survivin shRNA induced a higher number of apoptotic cells, compared with that in either the Livin shRNA or Survivin shRNA group $(\mathrm{P}<0.05) .{ }^{*} \mathrm{P}<0.05$ as compared with control. shRNA, short hairpin RNA.

shRNA transfection decreased the protein expression of Livin and Survivin. Co-transfection was more efficient than single transfection with either Survivin shRNA or Livin shRNA alone (Fig. 2).

CCK assay. As shown in Fig. 3, transfection with Livin shRNA and/or Survivin shRNA inhibited cell proliferation in the transfected A549 cells. The proliferation of cells in the co-transfection group exhibited a higher rate of growth inhibition, compared with that in either the Livin shRNA or Survivin shRNA transfection group $(\mathrm{P}<0.05)$.

Antitumor effects of shRNAs in vivo. In order to evaluate the antitumor effects of the shRNAs in vivo, the nude mice, which were implanted with tumor xenografts established using A549 cells, were injected with shRNA plasmids. As shown in Fig. 4, shRNA plasmid injection inhibited tumor growth significantly in the mice, compared with that in the control group, and double injection with Livin ShRNA and Survivin shRNA exerted a more marked effect, compared with that in the groups transfected with Livin shRNA or Survivin shRNA alone.

Analysis of apoptosis. As shown in Fig. 5A, after 48 h, transfection with Livin shRNA and/or Survivin shRNA enhanced cell apoptosis. The apoptotic rate was $55.40 \pm 5.48 \%$ in the co-transfection group, which was higher than that in either the Livin shRNA transfection group $(37.80 \pm 4.11 \%)$ or the Survivin shRNA transfection group $(42.61 \pm 3.99 \% ; \mathrm{P}<0.05)$. This indicated that Livin and Survivin shRNA co-transfection was more effective in promoting apoptosis.

As shown in Fig. 5B, the injection of Livin shRNA and/or Survivin shRNA induced apoptosis in the tumor tissues, and the number of apoptotic cells in the Livin shRNA and Survivin shRNA double injection group was higher, compared with the number of apoptotic cells in either the Livin shRNA injection group or the Survivin shRNA injection group $(\mathrm{P}<0.05)$. This suggested that Livin shRNA and Survivin shRNA double injection was more effective than either Livin shRNA or Survivin shRNA in inducing apoptosis in the tumor tissues.

\section{Discussion}

Lung cancer is one of the most common and life-threatening malignances worldwide, and remains one of the biggest challenges faced by physicians, with a mortality rate similar to that of breast and colorectal cancer combined, despite incidence being similar to that of breast or colorectal cancer (21). NSCLC remains the main subtype of lung cancer, accounting for $\sim 75 \%$ of all lung cancer cases. NSCLC is life threatening, with a five-year relative survival rate of $\sim 17 \%$ (22).

As cancer is one of the key targets of RNAi-based therapy, RNAi is important in cancer treatment. RNAi has high gene silencing efficiency, which can induce the silencing of advanced stages of tumor growth, transmitting the silenced gene to subsequent generations. It is also relatively low cost compared with other gene therapies, and has high specificity compared with cancer therapies, including chemotherapy (23). As RNAi-based therapy has high efficiency and specificity for gene silencing, a precise functional mechanism and fewer side effects, compared with chemotherapy, oncogenes and certain other genes involved in tumor formation and development are ideal gene silencing targets for RNAi-based therapy (23).

The IAP family members are regulators of apoptosis, cytokinesis and signal transduction, which are important in the process of cancer resistance to apoptosis and are produced in the processes of standard cytotoxic chemotherapy or radiotherapy. Therefore, cancer cells acquire mutations that allow them to survive apoptosis that are part of the transformation process or that may affect the growth and dissemination of the tumor (9). It had been reported that Survivin and Livin have are expressed at high levels in the majority of solid tumors, and it has been suggested that their expression is associated with prognostic significance (8). As Survivin and Livin appear to be novel promising targets in cancer therapy, Livin and Survivin shRNAs were established in the present study to silence their respective expression to examine the synergistic effect of the two IAPs in inhibiting apoptosis. The results of the RT-qPCR and western blot analyses demonstrated that the relative mRNA and protein expression levels were significantly 
decreased in the Livin and Survivin shRNA groups, and the effects were more marked in the Livin and Survivin shRNA co-transfection group, compared with either the Livin shRNA or Survivin shRNA single transfection groups alone. Yang et al previously reported that the knockdown of Livin, X-linked inhibitor of apoptosis (XIAP), and Survivin reduced the proliferation and transformation of high-grade bladder cancer T24 cells, but enhanced the apoptotic sensitivity of the cells to chemotherapy. In addition, the combined silencing of Livin, XIAP and Survivin significantly increased the levels of active caspase-3, active caspase-7, active caspase- 9 and cytosolic second mitochondria-derived activator of caspase (12).

In the present study, the results of xenograft tumor experiments showed that transfection with Livin or Survivin shRNA reduced tumor growth significantly, compared with that in the untreated group, and Livin and Survivin shRNA co-transfection led to a more marked reduction of tumor size, compared with that in the cells transfected with either vector alone.

In conclusion, the knockdown of both the Livin and Survivin genes by shRNAs may be a promising therapy in the treatment of cancer.

\section{Acknowledgements}

The present study was supported partly by grants from the National Natural Science Foundation of China (grant no. 81141093), the Science Foundation of the Fujian Province, China (grant no. 2013J01290), Technology Foundation for Selected Overseas Chinese Scholar, Ministry of Personnel of China (2012) and the Nursery Research Fund of Second Affiliated Hospital of Fujian Medical University (grant no. 2012MP73).

\section{References}

1. Gatti L, Cossa G, Tinelli S, Carenini N, Arrighetti N, Pennati M, Cominetti D, De Cesare M, Zunino F, Zaffaroni N and Perego P: Improved apoptotic cell death in drug-resistant non-small-cell lung cancer cells by tumor necrosis factor-related apoptosis-inducing ligand-based treatment. J Pharmacol Exp Ther 348: 360-371, 2014.

2. Janssen-Heijnen ML, van Steenbergen LN, Steyerberg E, Visser O, De Ruysscher DK and Groen HJ: Long-term excess mortality for survivors of non-small cell lung cancer in the Netherlands. J Thorac Oncol 7: 496-502, 2012.

3. Chung JH, Choi YS, Cho JH, Kim HK, Kim J, Zo JI and Shim YM: Uniportal video-assisted thoracoscopic lobectomy: An alternative to conventional thoracoscopic lobectomy in lung cancer surgery? Interact Cardiovasc Thorac Surg 20: 813-819, 2015.

4. Tacelli N, Santangelo T, Scherpereel A, Duhamel A, Deken V, Klotz E, Cortot A, Lafitte JJ, Wallyn F, Remy J and Remy-Jardin M: Perfusion CT allows prediction of therapy response in non-small cell lung cancer treated with conventional and anti-angiogenic chemotherapy. Eur Radiol 23: 2127-2136, 2013.

5. Takenaka T, Takenoyama M, Inamasu E, Yoshida T, Toyokawa G, Nosaki K, Hirai F, Yamaguchi M, Shimokawa M, Seto T and Ichinose Y: Role of surgical resection for patients with limited disease-small cell lung cancer. Lung Cancer 88: 52-56, 2015.
6. Donington JS, Koo CW and Ballas MS: Novel therapies for non-small cell lung cancer. J Thorac Imaging 26: 175-185, 2011.

7. Takahashi Y, Yamaoka K, Nishikawa M and Takakura Y: Quantitative and temporal analysis of gene silencing in tumor cells induced by small interfering RNA or short hairpin RNA expressed from plasmid vectors. J Pharm Sci 98: 74-80, 2009.

8. Gazzaniga P, Gradilone A, Giuliani L, Gandini O, Silvestri I, Nofroni I, Saccani G, Frati L and Aglianò AM: Expression and prognostic significance of LIVIN, SURVIVIN and other apoptosis-related genes in the progression of superficial bladder cancer. Ann Oncol 14: 85-90, 2003.

9. LaCasse EC, Mahoney DJ, Cheung HH, Plenchette S, Baird S and Korneluk RG: IAP-targeted therapies for cancer. Oncogene 27: 6252-6275, 2008

10. Guan HP, Sun JZ, Feng XL, Chen JS, Chen FJ, Cheng XF, Liu XW and Ni B: Effects of RNA interference-mediated knockdown of livin and survivin using monomethoxypolyethylene glycol-chitosan nanoparticles in MG-63 osteosarcoma cells. Mol Med Rep 13: 1821-1826, 2016.

11. Yang AQ, Wang PJ,Huang T, Żhou WL and Landman J: Effects of monomethoxypolyethylene glycol-chitosan nanoparticle-mediated dual silencing of livin and survivin genes in prostate cancer PC-3M cells. Genet Mol Res 5: 2016 doi: 10.4238/gmr.15027430.

12. Yang D, Song X, Zhang J, Ye L, Wang S, Che X, Wang J, Zhang Z, Wang $L$ and Shi W: Therapeutic potential of siRNA-mediated combined knockdown of the IAP genes (Livin, XIAP, and Survivin) on human bladder cancer T24 cells. Acta Biochim Biophys Sin (Shanghai) 42: 137-144, 2010.

13. Zhang Y, Huang H, Zhou H, Du T, Zeng L, Cao Y, Chen J, Lai Y, Li J, Wang $G$ and Guo Z: Activation of nuclear factor $k B$ pathway and downstream targets survivin and livin by SHARPIN contributes to the progression and metastasis of prostate cancer. Cancer 120: 3208-3218, 2014

14. McIntyre GJ and Fanning GC: Design and cloning strategies for constructing shRNA expression vectors. BMC Biotechnol 6: 1, 2006.

15. Zhao X, Yuan Y, Zhang Z, Feng X, Zhang J, Yuan X and Li J: Effects of shRNA-silenced livin and survivin on lung cancer cell proliferation and apoptosis. J BUON 19: 757-762, 2014.

16. Xu W, Chang H, Qin CK and Zhai YP: Impact of Co-transfection with livin and survivin shRNA expression vectors on biological behavior of HepG2 cells. Asian Pac J Cancer Prev 14: 5467-5472, 2013.

17. Kong X, Li L, Sun L, Fu K, Long J, Weng X, Ye X, Liu X, Wang B, Yan S, et al: Rapid diagnosis of aneuploidy using segmental duplication quantitative fluorescent PCR. PLoS One 9: e88932, 2014.

18. Mavridis K, Stravodimos K and Scorilas A: Downregulation and prognostic performance of microRNA 224 expression in prostate cancer. Clin Chem 59: 261-269, 2013.

19. Tirrò E, Consoli ML, Massimino M, Manzella L, Frasca F, Sciacca L, Vicari L, Stassi G, Messina L, Messina A and Vigneri P: Altered expression of c-IAP1, survivin, and Smac contributes to chemotherapy resistance in thyroid cancer cells. Cancer Res 66: 4263-4272, 2006.

20. Spänkuch B, Matthess Y, Knecht R, Zimmer B, Kaufmann M and Strebhardt K: Cancer inhibition in nude mice after systemic application of U6 promoter-driven short hairpin RNAs against PLK1. J Natl Cancer Inst 96: 862-872, 2004.

21. Custodio A, Méndez M and Provencio M: Targeted therapies for advanced non-small-cell lung cancer: Current status and future implications. Cancer Treat Rev 38: 36-53, 2012.

22. van der Drift MA, Karim-Kos HE, Siesling S, Groen HJ, Wouters MW, Coebergh JW, de Vries E and Janssen-Heijnen ML: Progress in standard of care therapy and modest survival benefits in the treatment of non-small cell lung cancer patients in the Netherlands in the last 20 years. J Thorac Oncol 7: 291-298, 2012.

23. Mansoori B, Sandoghchian Shotorbani S and Baradaran B: RNA interference and its role in cancer therapy. Adv Pharm Bull 4: 313-321, 2014. 